\title{
Hidrolisado proteico de resíduo de sardinha como atrativo alimentar para juvenis de jundiá
}

[Sardine waste protein hydrolisate as feeding stimulant for silver catfish juveniles]

\author{
J.A. Broggi ${ }^{1}$, B. Wosniak $^{1}$, J. Uczay ${ }^{1}$, M.L. Pessatti ${ }^{2}$, T.E.H.P. Fabregat ${ }^{1}$ * \\ ${ }^{1}$ Universidade do Estado de Santa Catarina - Florianópolis, SC \\ ${ }^{2}$ Universidade do Vale do Itajaí - Itajaí - SC
}

\begin{abstract}
RESUMO
O objetivo deste estudo foi avaliar a utilização do hidrolisado proteico de resíduo de sardinha como atrativo na alimentação do Rhamdia quelen. No experimento 1 , foram utilizados os seguintes atrativos alimentares: 1. extrato aquoso de músculo de tilápia-do-Nilo (controle positivo); 2. hidrolisado proteico de resíduo de sardinha com baixo grau de hidrólise $(\mathrm{GH}) ; 3$. hidrolisado proteico de resíduo de sardinha com alto GH; 4. hidrolisado proteico de resíduo de sardinha com alto GH diluído ( $10 \%$ da concentração) e 5. controle usando somente água destilada. Após jejum de 48 horas, o comportamento foi registrado em vídeo por um período basal de dois minutos e por mais 18 minutos após a inoculação do atrativo. $\mathrm{O}$ delineamento foi inteiramente ao acaso, com três tratamentos e 20 repetições. O experimento 2 foi realizado para avaliar a capacidade do hidrolisado proteico de estimular a ingestão de alimento em juvenis de jundiá. Para isso, foram confeccionados pellets de ágar contendo ou não hidrolisado proteico de resíduo de sardinha. Os peixes foram avaliados individualmente e tiveram um período de adaptação de sete dias. Os resultados foram analisados por meio do teste de proporção de Goodman (1964). A inoculação dos hidrolisados com alto e baixo $\mathrm{GH}$ aumentou o tempo de movimentação dos barbilhões. $\mathrm{O}$ hidrolisado com alto GH diluído proporcionou os mesmos resultados que o hidrolisado com baixo GH , mas as médias não diferiram das obtidas para a água destilada (controle negativo) e do extrato de músculo. $\mathrm{O}$ incremento na movimentação de um lado para outro do aquário foi maior $(\mathrm{P}<0,05)$ para os hidrolisados com alto e baixo GH. No experimento 2, a proporção de peixes que ingeriu os pellets contendo hidrolisado proteico de resíduo de sardinha com alto GH foi maior $(\mathrm{P}<0,05)$ em relação aos que ingeriram os pellets contendo água destilada. $\mathrm{O}$ hidrolisado proteico foi eficiente para estimular $\mathrm{o}$ comportamento associado à alimentação em juvenis de Rhamdia quelen.
\end{abstract}

Palavras-chave: peixe nativo, etologia, hidrólise, manejo alimentar

\begin{abstract}
The aim of this study was to evaluate the use of the sardine waste hydrolysate as a feeding stimulant for Rhamdia quelen juveniles. In experiment 1 the following feeding stimulants were evaluated: 1 . Aqueous extract of Nile tilapia muscle; 2. sardine waste protein hydrolysate with a low degree of hydrolysis (DH); 3. Sardine waste protein hydrolysate with high GH; 4. sardine waste protein hydrolysate with high GH diluted (10\% concentration) and 5. control using only distilled water. The fish were evaluated individually. After 48 hours fasting, the behavior was videotaped for a baseline period of 2 minutes, and for another 18 minutes after attractive inoculation. The design was completely randomized with three treatments and twenty repetitions. Experiment 2 was conducted to evaluate the effect of the sardine waste protein hydrolysate on the food intake of silver catfish. For this purpose agar pellets were produced containing or not sardine waste protein hydrolysate. The fish were evaluated individually and had an adjustment period of 7 days. The results were analyzed using the Goodman test (1964). Inoculation of the sardine waste protein hydrolysate with high and low GH increased the barbel movement time. The sardine waste protein hydrolyzate diluted with high GH yielded the same results as the hydrolysate with
\end{abstract}

Recebido em 7 de abril de 2015

Aceito em 7 de julho de 2016

*Autor para correspondência (corresponding author)

E-mail: thiagofabregat@hotmail.com 


\section{Broggi et al.}

low GH, but did not differ from the average obtained for distilled water (negative control) and muscle extract. The increase in moving side to side in the aquarium was higher $(P<0.05)$ for sardine waste protein hydrolysate with high and low GH. In experiment 2 the proportion of fish that ingested the pellets containing sardine waste protein hydrolysate was higher $(P<0.05)$ than the proportion of fish that ingested the pellets containing distilled water. The sardine waste protein hydrolysate was efficient to stimulate the feeding associated behavior in Rhamdia quelen juveniles.

Keywords: native fish, ethology, hydrolysis, feed management

\section{INTRODUÇ̃̃̃O}

Uma grande quantidade de resíduos do processamento de pescado é descartada diariamente pela indústria de pescado. No ano de 2012, foram capturadas 3,3 milhões de toneladas de sardinhas (Sardinella spp. e Sardina pilchardus) para o consumo humano, e esse produto gera uma quantidade significativa de resíduos que podem ser aproveitados em dietas para organismos aquáticos. Apenas $35 \%$ da farinha de peixe no mundo têm como fonte principal resíduos da indústria do pescado $(\mathrm{FAO}$, 2014). Uma das alternativas para o aproveitamento dos subprodutos da pesca é a utilização da hidrólise enzimática. Essa tecnologia consiste em transformar esses resíduos em um produto de alto valor biológico agregado (Chabeaud et al., 2009).

O elevado valor nutricional qualifica o hidrolisado proteico de pescado para ser utilizado na composição das rações em cultivos que demandam uma dieta de qualidade, como larviculturas (Hermannsdottir et al., 2009; Srichanun et al., 2014) e a produção de peixes carnívoros (Hevroy et al., 2005). A matéria seca do hidrolisado enzimático proteico de pescado pode ser utilizada em aquicultura como suplemento e para melhorar a digestibilidade da dieta (Oliva-Teles et al., 1999). Além disso, uma abordagem que ainda não foi devidamente aprofundada é a possibilidade de utilizar o hidrolisado proteico para melhorar a atratividade da dieta. Os aminoácidos livres e os peptídeos de baixo peso molecular encontrados no hidrolisado são detectados pelo sistema gustatório dos peixes e podem agir como atrativos alimentares (Halver e Hardy, 2002).

Rhamdia quelen é uma espécie endêmica do Brasil, de hábito alimentar onívoro, com preferência por peixes, crustáceos, insetos, restos vegetais e detritos orgânicos (Baldisserotto, 2009). O jundiá possui um sistema gustativo apurado, localizando o alimento por meio de substâncias dissolvidas na água. Assim como outras espécies de bagre, possuem corpúsculos gustativos nos barbilhões, na superfície da pele, nos lábios, nas partes superiores e no interior da boca e nos arcos branquiais (Atema, 1971). Isso revela a grande importância que a quimiorrecepção tem no comportamento alimentar desses peixes. Já foi relatada inclusive alta sensibilidade desse grupo de peixes a aminoácidos dissolvidos na água (Caprio, 1975). Nesse sentido, o uso de atrativos químicos na água pode ser uma estratégia para condicioná-los ao manejo alimentar em cativeiro. Assim, o objetivo do presente estudo foi avaliar a eficiência do hidrolisado proteico de sardinha como atrativo alimentar para juvenis de jundiá.

\section{MATERIAL E MÉTODOS}

Este experimento foi conduzido no Laboratório de Piscicultura do Centro de Ciências Agroveterinárias da Universidade do Estado de Santa Catarina. Os procedimentos presentes neste estudo foram aprovados pelo Comitê de Ética da Universidade do Estado de Santa Catarina (Protocolo 1.14.13). A estratégia básica foi avaliar o efeito do hidrolisado proteico de sardinha como estimulador químico do apetite para o jundiá. Para isso, foram realizados dois ensaios experimentais. No primeiro, foi avaliado o efeito da exposição a diferentes atrativos alimentares sobre o comportamento alimentar; no segundo, foi estudado o efeito do hidrolisado sobre a ingestão de alimento.

O hidrolisado proteico foi produzido com carcaças limpas (desprovidas de cabeça, cauda e vísceras) de sardinhas (Sardinella sp.). Alíquotas com cerca de $300 \mathrm{~g}$, totalizando $1,45 \mathrm{~kg}$ de amostra, foram homogeneizadas em liquidificador com três volumes de água e incubadas com a Protamex $^{\circledR}$ Novozymes A/S (1:500 enzima:peixe) a $50^{\circ} \mathrm{C}$, durante 90 
minutos, seguido de inativação da enzima a $90^{\circ} \mathrm{C}$, durante 15 minutos. As suspensões foram misturadas e submetidas à filtração Büchner com papel de $80 \mathrm{~g}$ Unifil $^{\circledR}$ e vácuo para um kitassato. $\mathrm{O}$ material retido foi considerado como a fração insolúvel, e a fração solúvel (filtrado) foi congelada e liofilizada.

Alternativamente, outra estratégia de separação foi realizada, com o intuito de se obter um hidrolisado com menor grau de hidrólise. Cerca de $1000 \mathrm{~g}$ de amostra foram homogeneizadas em liquidificador com $200 \mathrm{~mL}$ de água destilada e, em seguida, incubadas a $50^{\circ} \mathrm{C}$. Após estabilização da temperatura, foram adicionados $2 \mathrm{~g}$ de enzima diluída em $10 \mathrm{~mL}$ de água destilada. Decorrida a hidrólise, como descrito acima, a suspensão foi centrifugada a $650 \mathrm{xg}$. O sobrenadante (fração solúvel), obtido dessa forma, contém fragmentos proteicos maiores e um menor grau de hidrólise.

A composição dos hidrolisados está apresentada na Tab. 1. As análises químicas foram efetuadas de acordo com os métodos da Official... (1995). $\mathrm{O}$ teor de umidade foi determinado em analisador de umidade por infravermelho, e o teor de lipídeos pelos métodos de Soxhlet. O grau de hidrólise $(\mathrm{GH} \%)$ foi determinado por metodologia modificada por Nielsen et al. (2001). A análise consiste na quantificação da proporção de grupamentos amino-livres na fração solúvel do hidrolisado de proteína, pela reação desses grupamentos com 0 ophthaldialdehyde (OPA), em relação à proteína total da matéria-prima, determinada pelo método de Kjeldahl (Official..., 1995).

Tabela 1. Composição dos hidrolisados

\begin{tabular}{ccccc}
\hline Amostra & Umidade (\%) & Proteína* (\%) & Lipídeo* (\%) & GH (\%) \\
\hline Hidrolisado de baixo GH & $76,6 \pm 0,1$ & $73,4 \pm 2,0$ & $6,4 \pm 1,4$ & 5,9 \\
Hidrolisado de alto GH & $96,2 \pm 0,2$ & $82,5 \pm 1,8$ & $2,4 \pm 0,1$ & 22,2 \\
\hline
\end{tabular}

*Valores baseados na matéria seca. GH - grau de hidrólise.

Antes de cada um dos experimentos, os juvenis de jundiá (peso médio 7,3 $\pm 1,8 \mathrm{~g}$ ) foram aclimatados em biotério por, no mínimo, 30 dias, em caixas d'água equipadas com sistema de aeração e aquecimento. Os animais foram alimentados com ração comercial e as excretas e restos alimentares eram sifonados diariamente. A qualidade da água foi monitorada periodicamente e as médias foram: temperatura $24,72^{\circ} \mathrm{C} \pm 0,91$; oxigênio $5,24 \mathrm{mg} / \mathrm{L} \pm 0,41$; amônia $0,01 \mu / \mathrm{L} \pm 0,1$ e $\mathrm{pH} 8,16 \pm 0,25$, mantidos dentro dos parâmetros recomendados para o cultivo do jundiá (Baldisseroto e Radünz, 2004).

O experimento 1 foi conduzido para avaliar como diferentes atrativos alimentares afetam o comportamento alimentar de juvenis de jundiá. Para isso, os seguintes atrativos alimentares foram avaliados: 1. extrato aquoso de músculo de tilápia-do-Nilo (controle positivo); 2. hidrolisado proteico de sardinha com baixo grau de hidrólise (GH); 3. hidrolisado proteico de sardinha com alto $\mathrm{GH} ; 4$. hidrolisado proteico de sardinha com alto $\mathrm{GH}$ diluído ( $10 \%$ da concentração) e 5 . controle usando somente água destilada. O delineamento experimental foi inteiramente ao acaso, com cinco tratamentos e, no mínimo, 15 repetições.

Os peixes foram avaliados individualmente e, antes dos ensaios, foram mantidos isolados nos aquários experimentais (20 litros), por um período máximo de sete dias, até eles começarem a se alimentar normalmente. Foram utilizados somente aqueles que estavam se alimentando por três dias seguidos. As avaliações foram realizadas sempre no mesmo horário, em dias diferentes, evitando-se, assim, interferência do ritmo circadiano nas variáveis estudadas.

Na preparação do extrato aquoso de músculo de tilápia, as amostras de tecido $(0,5 \mathrm{~g})$ foram maceradas, homogeneizadas em $10 \mathrm{~mL}$ de água destilada, coadas em peneira e misturadas em água destilada ate completar $40 \mathrm{~mL}$. Por último, a mistura foi filtrada em papel-filtro de $90 \mathrm{~mm}$, fracionada de acordo com a necessidade de uso e armazenada em freezer a $-20^{\circ} \mathrm{C}$. Nas avaliações, foram utilizados $20 \mathrm{~mL}$ de extrato de músculo de tilápia, quantidade que já foi utilizada com sucesso para o pintado (Vicensotto, 2003). A quantidade utilizada dos hidrolisados foi determinada de forma a incluir nos aquários uma 


\section{Broggi et al.}

quantidade de proteína equivalente à contida no extrato aquoso de músculo de tilápia $(2,23 \mathrm{mg} / \mathrm{L}$ do aquário). Antes da aplicação, o hidrolisado foi diluído em $20 \mathrm{~mL}$, de forma a padronizar o volume de líquido introduzido nos aquários.

Após um jejum de 48 horas, o comportamento basal dos peixes foi registrado em vídeo por um período de dois minutos $\mathrm{P} 1(0 \mathrm{a} 2 \mathrm{~min}=$ basal $) \mathrm{e}$, em seguida, foi introduzido o atrativo (ou água destilada), utilizando-se uma seringa ligada a uma cânula. $\mathrm{O}$ comportamento do peixe foi filmado durante mais 18 (totalizando 20) minutos. Foram registrados e analisados os seguintes parâmetros: a) o tempo em locomoção, independentemente do sentido ou da direção do movimento; b) o comportamento associado à alimentação, caracterizado pelo movimento contínuo ou levantamento dos barbilhões em direção ao alimento, de acordo com Giaquinto e Volpato (2001) e Vicensotto (2003); e c) o número de vezes que o peixe cruzou a linha divisória do meio do aquário. Os peixes que não se locomoveram nenhuma vez foram excluídos da análise estatística. Os resultados foram analisados por meio de análise de variância paramétrica (ANOVA) e submetidos ao teste de Duncan (5\% de significância). Antes de todas as análises, foi verificada a normalidade dos erros (Cramer-von-Mises) e homocedasticidade das variâncias (teste de Levene).

O experimento 2 foi conduzido para avaliar se o hidrolisado proteico seria capaz de estimular a ingestão de alimento em juvenis de jundiá. Para isso, foram confeccionados pellets de ágar contendo ou não hidrolisado proteico de resíduo de sardinha. O delineamento foi inteiramente ao acaso, com dois tratamentos e 20 repetições.

Os peixes foram avaliados individualmente, e antes dos ensaios foram mantidos isolados nos aquários experimentais (40 litros), por um período máximo de sete dias, até eles começarem a se alimentar normalmente. Foram utilizados somente aqueles que estavam se alimentando por três dias seguidos. As avaliações foram realizadas sempre no mesmo horário, em dias diferentes, evitando-se, assim, interferência do ritmo circadiano nas variáveis estudadas.

Os pellets foram produzidos com o hidrolisado proteico de resíduo de sardinha com alto $\mathrm{GH}$ (Tab. 1) e com água destilada. Como agente aglutinante, foram adicionados $3 \%$ de ágar, seguindo metodologia já utilizada por outros autores na avaliação de atrativos alimentares (Bórquez e Cerqueira, 1998). Foi adicionado 1\% de cantaxantina para pigmentar os pellets e facilitar a visualização. No dia das avaliações, foram fornecidos três pellets por aquário. Após 30 minutos, as sobras foram retiradas e o consumo foi quantificado. Os resultados foram analisados por meio do teste de proporção de Goodman (1964).

\section{RESULTADOS}

No experimento 1, a inoculação dos hidrolisados com alto e baixo GH estimulou a movimentação dos barbilhões $(\mathrm{P}<0,05$; Fig. 1). O hidrolisado com alto $\mathrm{GH}$ proporcionou maior movimentação $(\mathrm{P}<0,05)$ em relação aos outros tratamentos. $\mathrm{O}$ uso do hidrolisado com alto $\mathrm{GH}$ diluído proporcionou os mesmos resultados $(\mathrm{P}>0,05)$ que o hidrolisado com baixo GH. Não houve diferença na movimentação dos barbilhões entre a água destilada (controle negativo) e o extrato de músculo.

A porcentagem do tempo que os peixes ficaram se locomovendo aumentou $(\mathrm{P}<0,05)$ após a inoculação dos atrativos em relação ao periodo basal, de 3,33 $\pm 10,48$ para $17,01 \pm 22,07 \%$ do tempo, mas o incremento na locomoção não diferiu $(\mathrm{P}<0,05)$ entre os tratamentos. Por outro lado, a aplicação dos atrativos interferiu no número de vezes que os peixes cruzaram a linha divisória do meio do aquário (Fig. 3). O incremento na movimentação de um lado para outro do aquário foi maior $(\mathrm{P}<0,05)$ para os hidrolisados com alto e baixo $\mathrm{GH}$. Os resultados do extrato de músculo e do hidrolisado com alto $\mathrm{GH}$ diluído não diferiram $(\mathrm{P}>0,05)$ do hidrolisado com baixo $\mathrm{GH}$, mas também não variaram $(\mathrm{P}>0,05)$ em relação à água destilada. 


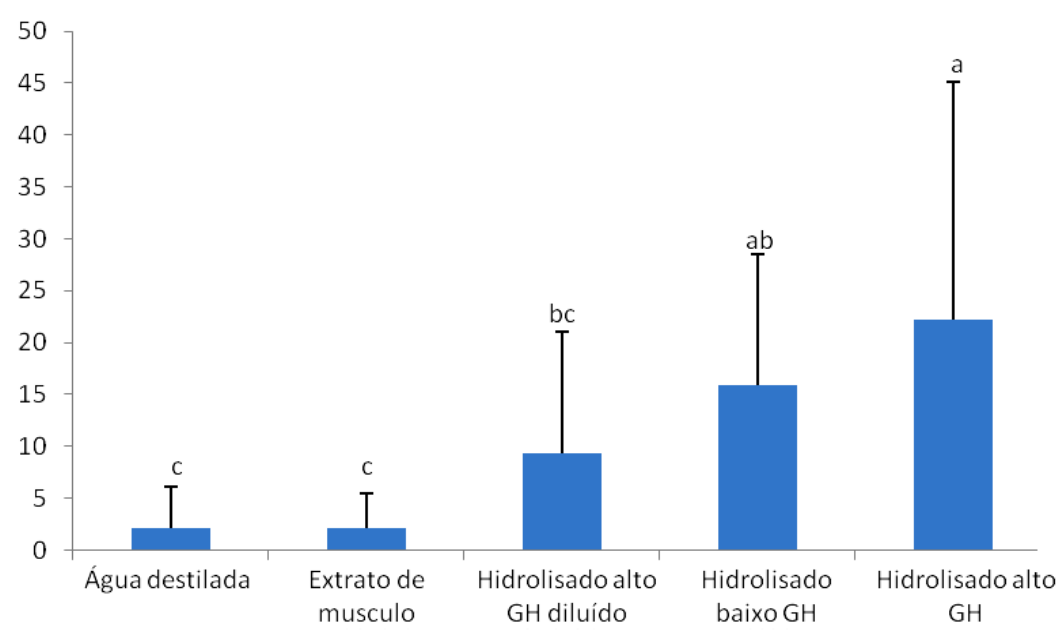

Figura 1. Incremento no tempo de movimentação dos barbilhões (\%) de juvenis de jundiá expostos a diferentes atrativos alimentares dissolvidos na água do aquário. Médias seguidas de letras diferentes diferem pelo teste de Duncan $(\mathrm{P}<0,05)$.

$\mathrm{Na}$ Tab. 2, estão apresentados os resultados do experimento 2. A proporção de peixes que ingeriram os pellets contendo hidrolisado proteico de resíduo de sardinha foi maior $(\mathrm{P}<0,05)$ em relação aos que ingeriram os pellets contendo água destilada.

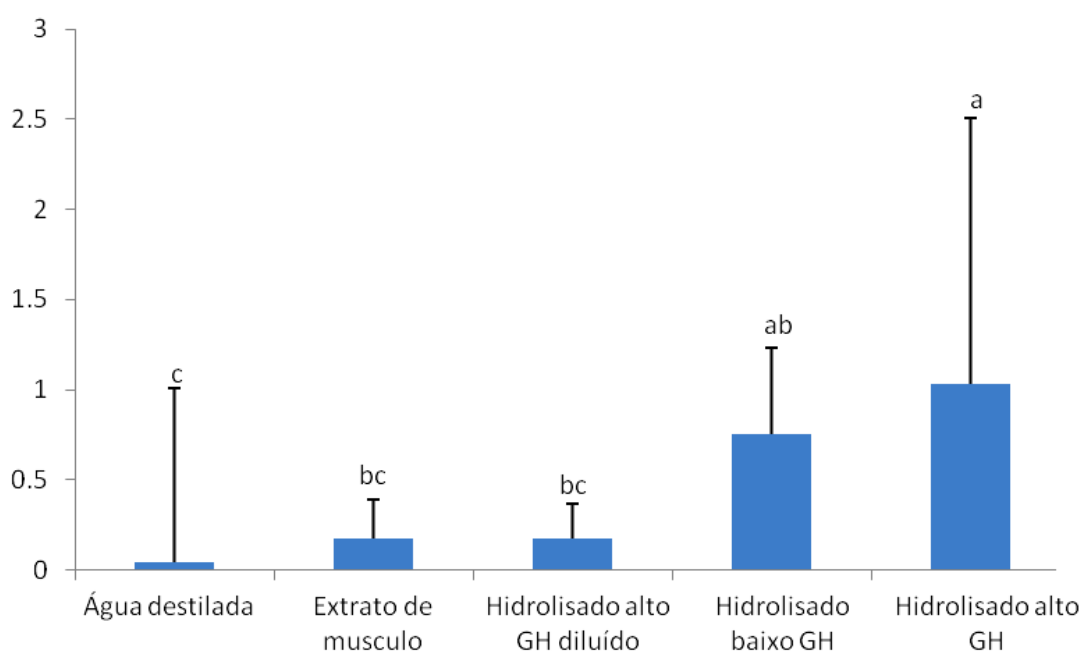

Figura 2. Incremento no número de vezes que juvenis de jundiá cruzaram o meio do aquário por minuto depois de expostos às substâncias dissolvidas na água. Médias seguidas de letras diferentes diferem pelo teste de Duncan $(\mathrm{P}<0,05)$.

Tabela 2. Resultados de teste de ingestão

\begin{tabular}{lcc}
\multicolumn{1}{c}{ Amostra } & $\begin{array}{c}\text { Total de peixes que } \\
\text { se alimentaram }\end{array}$ & $\begin{array}{c}\text { Total de } \\
\text { peixes }\end{array}$ \\
\hline $\begin{array}{l}\text { Hidrolisado } \\
\text { com alto GH }\end{array}$ & $13 \mathrm{a}$ & 19 \\
Água destilada & $3 \mathrm{~b}$ & 20 \\
\hline
\end{tabular}

Valores seguidos por letras diferentes diferem entre si pelo teste de Goodman $(\mathrm{P}<0,05)$. GH - grau de hidrólise.

\section{DISCUSSÃO}

A inoculação do hidrolisado de sardinha na água foi eficiente para estimular a movimentação dos barbilhões, comportamento já associado à procura pelo alimento para o pintado (Pseudoplatystoma coruscans), outra espécie de bagre (Giaquinto e Volpato, 2001). O hidrolisado proteico de pescado já foi amplamente avaliado 
como componente nutricional das dietas (Refstie et al., 2004; Cahu et al., 1999; Bui et al., 2014), mas seu potencial como atrativo foi pouco estudado. Nascimento et al. (2008) não trabalharam especificamente com 0 comportamento alimentar, mas relataram melhora no consumo de ração com a utilização de hidrolisados de peixe incorporados na dieta do pintado. Para o salmão-do-atlântico (Salmo salar), a inclusão do hidrolisado proteico de pescado na ração também estimulou o consumo de alimento (Refstie et al., 2004). O uso de hidrolisado de pescada-do-pacífico (Merluccius productus), adicionado em dietas para o salmão-chinook (Oncorhynchus tshawytscha), demonstrou ser um bom atrativo, reduzindo problemas relacionados à palatabilidade de dietas contendo níveis elevados de farelo de soja (Ho et al., 2014).

Vários estudos foram realizados com o uso de substâncias atrativas para camarões, com o objetivo de entender o comportamento alimentar desses crustáceos e gerar subsídios para técnicas que possam ser aplicadas no manejo nutricional dessas espécies (Sanchez et al., 2005; Smith et al., 2005; Nunes et al., 2006; Grey et al., 2009). Por outro lado, para peixes de água doce não existem muitos trabalhos envolvendo o uso de atrativos (Erketen e Nezaki, 2002; Barnard, 2006). Os bagres, que são peixes de fundo, onde o campo visual é limitado, a capacidade quimiorreceptora é mais eficiente que o sistema visual para a captura do alimento (Iwai, 1980). Para essas espécies, a palatabilidade das dietas é importante e o uso de atrativos como ferramentas de manejo pode maximizar os resultados de crescimento e sobrevivência.

A resposta comportamental foi mais evidente no hidrolisado de sardinha com alto GH (Fig. 4). Quanto maior o grau de hidrólise, maior a proporção de proteínas solúveis de baixo peso molecular, o que pode ter favorecido a detecção pelo sistema gustativo dos peixes, que são altamente sensíveis a substâncias solúveis dissolvidas na água (Halver e Hardy, 2002). Da mesma forma, a diluição do hidrolisado diminuiu a sua efetividade como atrativo, pela menor quantidade dessas substâncias na água. Esses resultados mostram que a concentração de atrativo utilizada tem efeito importante na resposta estimulatória, conforme já aventado por Kotzamanis et al. (2007).
O uso dos atrativos alimentares não afetou a locomoção dos peixes. Os hidrolisados foram eficientes para estimular o comportamento alimentar, mas não fizeram com que os peixes se movimentassem por mais tempo. O tempo de locomoção varia bastante entre os indivíduos e está sujeito a diversos fatores, até mesmo a diferenças individuais no comportamento associadas a diferentes perfis de personalidade (Brown et al., 2007). Assim, possíveis alterações no tempo de locomoção entre os tratamentos podem ter sido mascaradas.

Embora não tenha havido diferença na locomoção, o uso dos hidrolisados fez com que os peixes cruzassem com maior frequência a linha divisória do meio do aquário. Os atrativos foram inoculados no aquário e rapidamente se dissolveram de forma homogênea, na água do aquário. $\mathrm{O}$ comportamento de percorrer $\mathrm{o}$ aquário pode ser um indicativo de que os peixes estavam tentando localizar a fonte do estímulo químico. A procura pelo alimento é uma das etapas do comportamento alimentar e pode ser estimulada com o uso de substâncias incitantes (Barnard, 2006). Conforme descrito por Kasumyan e Doving (2003), a resposta gustatória extraoral, quando bem desenvolvida, faz o animal exercer um esforço abrupto para localizar o objeto ou evitá-lo, desenvolvendo movimentos de parar, retornar, virar para o lado, nadar para trás, iniciar a trajetória de procura ou fazer círculos e movimento de zigue-zague para procurar o objeto.

O extrato de músculo foi utilizado como um controle positivo, pois sua efetividade já foi comprovada para o pintado (Vicensotto, 2003). Entretanto, para o jundiá, os resultados de estimulação não foram suficientes para mostrar uma resposta em relação ao tratamento controle. Esse resultado pode estar associado a diferenças no hábito alimentar das duas espécies, pois o pintado é um peixe predador carnívoro (Sato, 2003). Embora o jundiá também possa ingerir pequenos peixes, na verdade trata-se de uma espécie onívora com tendência à carnívora (Fracalossi et al., 2004). Pelo fato de o jundiá ser um peixe de hábito onívoro e, portanto, não ser um predador agressivo, ele pode ter interpretado a presença do extrato de músculo como indicativo da presença de um peixe carnívoro por perto, não havendo, assim, um estímulo. 
Os atrativos podem ser utilizados de duas formas: diretamente na água dos tanques, para estimular o início da alimentação (Caprio, 1975; Barnard, 2006), e na ração, para maximizar a ingestão de dietas com baixa atratividade (Erketen e Nezaki, 2002; Barnard, 2006). O hidrolisado de sardinha inoculado na água do aquário foi eficiente para estimular o comportamento associado à alimentação em juvenis de jundiá, assim como sua inclusão em pellets foi eficiente para estimular o consumo deles. Esses resultados mostram que os hidrolisados são eficientes como atrativos e podem ser adicionados em dietas com o objetivo de favorecer o consumo de ração e melhorar o desempenho dos peixes.

\section{CONCLUSÕES}

O uso de hidrolisado proteico de sardinha se mostrou eficiente para estimular o comportamento que está associado à alimentação dos juvenis de jundiá, assim como a ingestão de alimento. A fração solúvel do hidrolisado estimulou o comportamento alimentar e favoreceu a busca por alimento.

\section{REFERÊNCIAS}

ATEMA, J. Structures and functions of the sense of taste in the catfish (Ictalurus natalis). Brain Behav. Evol., v.4, p.273-294, 1971.

BALDISSEROTTO, B.; RADÜNZ, J.N. Criação de jundiá. Santa Maria: UFSM, 2004. 232p.

BALDISSEROTTO, B. Piscicultura continental no Rio Grande do Sul: situação atual, problemas e perspectivas para o futuro. Cienc. Rural, v.39, p.291-299, 2009.

BARNARD, P. Gustatory and olfactory feedeing responces in Japanese Koi carp (Cyprinus carpio). 2006. 67f. Tese (Doctor) - Curso de Faculty of Agricultural Sciences, Department de Animal Science, University of Stellenbosch, Stellenbosch, RSA.

BÓRQUEZ, A.; CERQUEIRA, V.R. Feeding behavior in juvenile snook Centropomus undecimalis. I. Individual effect of some chemical substances. Aquaculture, v.169, p.2535, 1998.
BROWN, C.; JONES, F.; BRAITHWITE, V. In situ examination of boldness-shyness traits in the tropical poeciliid, Brachyraphis episcope. Anim. Behav., v.70, p.1003-1009. 2007.

BUI, H.T.D.; KHOSRAVI, S.; FOURNIER, V. et al Growth performance, feed utilization, innate immunity, digestibility and disease resistance of juvenile red seabream (Pagrus major) fed diets supplemented with protein hydrolysates. Aquaculture, v.418, p.11-16. 2014.

CAPRIO, J. High sensitive of catfish taste receptors to amino acids. Comp. Biochem. Physiol., v.52, p.247-251, 1975.

CHABEAUD, A.; VANDANJON, L.; BOURSEAU, P. et al. Fractionation by ultrafiltration of a saithe protein hydrolysate (Pollachius virens): effect of material and molecular weight cut-off on the membrane performances. J. Food Process. Eng., v.91, p.408-414, 2009.

ERTEKEN, A.; NEZAKI, G. Effects of feeding stimulants, and diet $\mathrm{pH}$ on the growth of Black Sea Turbot, Psetta maxima. Turk. J. Fish. Aquat. Sci, p.19-22, 2002.

FOOD AND AGRICULTURE ORGANIZATION OF THE UNITED NATIONS. The state of world fisheries and aquaculture. Rome: FAO, 2014. $110 \mathrm{p}$.

FRACALOSSI, D.M.; MEYER, G.; SANTAMARIA, F.M. et al. Desempenho do jundiá, Rhamdia quelen, e do dourado, Salminus brasiliensis, em viveiros de terra na região sul do Brasil. Acta Sci. Anim. Sci., v.26, p.345-352, 2004.

GIAQUINTO, P.C.; VOLPATO, G.L. Hunger suppresses and the onset and the freezing component of the antipredator response to conspecific skin extract in pintado catfish. Behaviour, v.138, p.1205-1214, 2001.

GOODMAN, L.A. Simultaneous confidence intervals for contrasts among multinomial populations. Ann. Math. Stat., v.35, p.716-725, 1964.

GREY, M.; FORSTER, I.; DOMINY, W. Validation of a feeding stimulant bioassay using fish hydrolysates for pacific white shrimp, Litopenaeus vannamei. J. World Aquat. Soc., v.40, p.547-555, 2009.

HALVER, J.E.; HARDY, R.W. Fish nutrition. 3.ed. San Diego: Elsevier Science, 2002. 839p. 
HERMANNSDOTTIR, R.; JOHANNSDOTTIR, J.; SMMARADOTTIR, S. et al. Analysis of effects induced by a pollock protein hydrolysate on early development, innate immunity and the bacterial community structure of first feeding of Atlantic halibut (Hippoglossus hippoglossus L.) larvae. Fish Shellfish Immunol., v.27, p.595-602, 2009.

HEVROY, E.M.; ESPE, M.; WAAGBO, R. et al. Nutrient utilization in Atlantic salmon (Salmo salar L.) fed increased levels of fish protein hydrolysate during a period of fast growth. Aquacult. Nutr., v. 11, p.301-313, 2005.

HO, T.C.W.; LI-CHAN, E.C.Y.; SKURA, B.J. et al. Pacific hake (Merluccius productus Ayres, 1855) hydrolysates as feed attractants for juvenile Chinook salmon (Oncorhynchus tshawytscha Walbaum, 1792). Aquac. Res., v.45, p.1140-1152, 2014.

IWAI, T. Sensory anatomy and feeding of fish larvae. In: I CLARM CONFERENCE, 5., 1980, Manila. Fish behaviour and its use in the capture and culture of fishes. Proceedings... Manila, Philippines: [s.n.], 1980. p.124-145.

KASUMYAN, A.O.; DOVING, K.B. Taste preferences in fishes. Fish Fish., v.4, p.289-347, 2003.

KOTZAMANIS, Y.P.; GISBERT, E; GATESOUP, F.G. et al. Effects of different dietary levels of fish protein hydrolysates on growth, digestive enzymes, gut microbiota, and resistance to Vibrio anguillarum in European sea bass (Dicentrarchus labrax) larvae. Comp. Biochem. Phys., A. p.205-214, 2007.

NASCIMENTO, J.H.P.; VERRESCHI, D.C.; JESUS, R.S. Hidrolisado proteico de peixe em dietas para alevinos de surubim, Pseudoplatystoma coruscans (Agassiz, 1829). Rev. Bras. Hig. Sanid. Anim., v.2, p.1-6, 2008.

NIELSEN, P.M.; PETERSEN, D.; DAMBMANN, C. Improved method for determining food protein degree of hydrolysis. $J$. Food Sci., v.66, p.642-646, 2001.
NUNES, A.J.P.; SÁ, M.V.C.; ANDRIOLANETO, F.F. et al. Behavioral response to selected feed attractants and stimulants in Pacific white shrimp, Litopenaeus vannamei. Aquaculture, v.260, p.244-254, 2006.

OLIVA-TELES, A.; CERQUEIRA, A.L.; GONÇALVES, P. The utilization of diets containing high levels of fish protein hydrolysate by turbot (Scophthalmus maximus) juveniles. Aquaculture, v.179, p.195-201, 1999.

OFFICIAL methods of analysis. 16.ed. Arlington: AOAC, 1995.

REFSTIE, S.; OLLI, J.J.; STANDAL, H. Feed intake, growth, and protein utilization by postsmolt Atlantic salmon (Salmo salar) in response to graded levels of fish protein hydrolysate in the diet. Aquaculture, v.239, p.331-349, 2004.

SANCHEZ, D.R.; FOX, J.M.; LAWRENCE, A.L. et al. A methodology for evaluation of dietary feeding stimulants for the Pacific White shrimp, Litopenaeus vannarnei. J. World Aquat. Soc., v.36, p.14-23, 2005.

SATO, Y; GODINHO, H.P. Migratory fishes of the São Francisco River. In: CAROLSFELD, J.; HARVEY, B.; ROSS, C.; BAER, A. Migratory fishes of south America biology, fisheries and conservation status. Ottawa: International Development Research Centre, 2003. p.195-232.

SMITH, D.M.; TABRETT, S.J.; BARCLAY, M.C. et al. The efficacy of ingredients included in shrimp feeds to stimulate intake. Aquac. Nutr., v.11, p.263-271, 2005.

SRICHANUN, M.; TANTIKITTI, C.; KORTNER, T.M. et al. Effects of different protein hydrolysate products and levels on growth, survival rate and digestive capacity in Asian seabass (Lates calcarifer Bloch) larvae. Aquaculture, v.428, p.195-202, 2014

VICENSOTTO JÚNIOR, M. Estimulação química do apetite e crescimento do pintado. 2003. 30f. Dissertação (Mestrado) - Curso do Centro de Aquicultura, Universidade Estadual Paulista, Jaboticabal, SP. 